\title{
Avaliar a avaliação: um caminho para aperfeiçoar o Programa Nacional do Livro Didático
}

\begin{abstract}
Marco Antonio Silva ${ }^{1}$
SPOSITO, Maria Encarnação Beltrão (Org). Livros didáticos de Geografia e História: avaliação e pesquisa. São Paulo: Cultura Acadêmica, 2006.

O Programa Nacional do Livro Didático (PNLD), pela ação do Ministério da Educação, transformou o governo brasileiro no maior comprador de livros do mundo. Para o ano de 2007, as aquisições previstas superam a casa dos 120 milhões de exemplares e o valor negociado com as editoras, nas compras para o Ensino Fundamental, foi de $\mathrm{R} \$ 456.706 .333,38$. Além disso, em grande parte das salas de aula, o livro didático tornou-se instrumento indispensável ao andamento das disciplinas e é o único material de leitura que adentra diversos lares brasileiros. Em 2007, especialmente, professores das séries finais do Ensino Fundamental de escolas públicas escolheram as coleções didáticas que serão adquiridas pelo PNLD para que os estudantes possam utilizálas nos próximos três anos.

Neste contexto, é oportuno o trabalho organizado por Sposito, que, dez anos após a primeira avaliação sistemática produzida no Brasil sobre os livros didáticos destinados à escola pública de Ensino Fundamental, faz uma revisão do processo de apreciação dos livros,
\end{abstract}

\footnotetext{
1 Mestrando da FaE/UfMG. Professor da Rede Particular e da Rede Municipal de Belo Horizonte.
} 
apresentando importantes subsídios aos interessados em repensar a seleção das obras de História e Geografia e o próprio PNLD. A autora faz um balanço da trajetória dos sete PNLDs de Geografia e História e apresenta seis artigos e quatro depoimentos de pesquisadores e acadêmicos envolvidos no processo, fazendo um recorte temporal que enfatiza, sobretudo, o intervalo entre os anos de 1997 e 2005, com destaque para o período 2001/2004, em que a Universidade Estadual Paulista (UNESP) foi responsável pela Coordenação do PNLD.

No primeiro capítulo, assinado pela organizadora do livro e coordenadora institucional dos PNLDs 2004 e 2005, afirma-se a importância dos processos de avaliação na contemporaneidade, enfatizando-se as políticas públicas governamentais e, em particular, a avaliação dos livros didáticos adquiridos pelo Fundo Nacional de Desenvolvimento da Educação (FNDE). Recorre-se a justificativas teóricas mais abrangentes, nos campos filosófico, político e econômico, para o processo de avaliação, na tentativa de contribuir para a superação de posições comuns e simplistas, como, por exemplo, ser contra ou a favor da avaliação dos livros didáticos apenas por princípio. Relativizamse posições como as de Osvaldo Coggiola (p. 20), que questiona a forma "inconteste" com que a implementação dos programas de avaliação estatais (ENC, Saeb, Enem, PNLD, Sistema Nacional de Avaliação da Pós-Graduação) tem se apresentado à sociedade, inclusive identificando as oposições à proposta como ideológicas ou resultantes de corporativismo acadêmico, ou do que chama de "burburinho sindical". Argumenta-se que propostas avaliativas alternativas, embasadas nas realidades latino-americanas e em diálogo com padrões internacionais de qualidade, podem, devem e estão sendo construídas.

Defendendo que o critério avaliativo adotado pelo PNLD contribuiu substancialmente para a melhoria da qualidade dos livros didáticos produzidos no Brasil, Holien Gonçalves Bezerra e Tânia Regina 
de Luca desenvolvem, no capítulo seguinte, um balanço do Programa e apresentam seus impactos sobre a oferta de livros de História mais sintonizados com a historiografia e os conhecimentos sobre ensinoaprendizagem produzidos na academia. Descrevem as políticas públicas brasileiras adotadas desde o século XIX para o livro didático, passando pelas intervenções abruptas do Estado Novo; as políticas de financiamento, a partir da década de 1960, com a ampliação da oferta de vagas; os órgãos criados durante a ditadura militar para cuidar do mercado editorial; a criação da Fundação de Assistência ao Educando, em 1983; o surgimento do PNLD, em 1985; as políticas de controle do Estado sobre a qualidade dos livros produzidos na década de 1990; e finalizam com a descentralização das políticas de avaliação, no começo do século XXI, quando a UNESP assumiu a coordenação dos trabalhos de avaliação dos livros didáticos de Geografia e História. Em seguida, demonstram que o modelo de avaliação dos livros didáticos estabelecido em 1995 foi sendo aprimorado nos PNLDs subseqüentes. Apresentam os critérios utilizados na avaliação dos livros de História: existência de metodologia de ensinoaprendizagem consistente e coerente, adoção de metodologias próprias da disciplina história, qualidade e consistência do manual do professor e, por fim, aspectos editoriais. Por meio de um levantamento quantitativo, é apresentada a avaliação dos livros e coleções inscritos ao longo dos diversos PNLDs, seguida de comentários sucintos sobre os processos marcantes de cada etapa. Por fim, os autores elencam uma série de avanços positivos e algumas ressalvas sobre o que os sete processos avaliativos do PNLD trouxeram para a produção dos livros didáticos de História no Brasil e levantam algumas questões que necessitam ser pesquisadas.

O capítulo três, assinado por Eliseu Sarvério Sposito, descreve as tensões geradas entre os diversos agentes envolvidos no processo de avaliação: autores e editoras de livros didáticos, pareceristas, professores, 
diretores de escolas, coordenadores pedagógicos e o próprio Estado. Apresenta os critérios adotados na avaliação dos livros no PNLD 2002 e o perfil dos profissionais solicitado pelo MEC para compor a equipe de pareceristas. Em suas considerações finais, defende a manutenção da política de avaliação dos livros didáticos, pois ela tem contribuído para que autores, editores, professores e alunos acreditem que um bom produto pedagógico é necessário para estimular e consolidar o ensino fundamental no país. Registra, ainda, que uma parcela de autores de livros didáticos que se posicionou contrariamente à avaliação, posteriormente compreendeu a seriedade, a qualidade e a validade do processo, incorporando mudanças a partir das críticas feitas pelo Guia do Livro Didático às suas obras.

Antonio Nivaldo Hespanhol, no capítulo seguinte, apresenta resumidamente o processo de avaliação para o PNLD 2005, que se iniciou três anos antes. Descreve o perfil da equipe de avaliadores, a dinâmica e as etapas de organização do trabalho e os critérios comuns de eliminação e classificação das obras utilizadas em todas as áreas do conhecimento. Destaca que a Geografia, em particular, adotou como critérios eliminatórios a incoerência e a inadequação metodológicas dos livros, a existência de erros em conceitos e em informações básicas e, por fim, a ausência de contribuição para a construção da cidadania. Em seguida, Hespanhol explica os critérios classificatórios para as coleções aprovadas: adequação da linguagem ao público-alvo; apresentação de diferentes pontos de vista sobre um mesmo assunto no decorrer da obra; problematização do conteúdo apresentada como estratégia pedagógica para desenvolver o senso crítico, estimular a curiosidade e a criatividade do aluno; consistência do conteúdo e correção conceitual; indicações corretas de fontes e outros autores citados; utilização de textos complementares de boa qualidade; inclusão criteriosa de glossário e referências bibliográficas; qualidade do projeto gráfico-editorial e do 
manual do professor. Ao final, são apresentadas as estatísticas das coleções excluídas e aprovadas e o ranking das coleções na classificação final. Nas considerações finais, o autor defende a manutenção de um processo de avaliação dos livros didáticos como meio de garantir a elevação do nível de qualidade das obras. Aponta a necessidade de manutenção de equipes independentes do MEC no processo avaliativo como ferramenta importante para garantir o aprimoramento da qualidade do livro didático no Brasil e como elemento de significativa contribuição na transparência do processo de produção e aquisição das obras.

Luiza H. S. Christov, no quinto artigo, descreve sucintamente as etapas e a metodologia de uma pesquisa qualitativa realizada com a participação de membros da equipe de pareceristas do PNLD sobre os processos de escolha dos livros didáticos realizados por professores das séries iniciais do Ensino Fundamental. Desenvolvida em municípios de diferentes portes demográficos e econômicos, escolas com realidades socioeconômicas e infra-estrutura distintas e que adotaram livros com maior ou menor qualidade, segundo a avaliação do Guia do Livro Didático, a pesquisa tentou focar a heterogeneidade da realidade brasileira. O objetivo era conhecer um pouco mais do universo dos atores que constroem cotidianamente as práticas escolares e perceber em que medida a avaliação dos pareceristas contribui para a escolha dos livros didáticos.

No sexto e último capítulo, Luca, Sposito e Christov apresentam alguns resultados da pesquisa descrita no capítulo anterior. Entre as conclusões apontadas, registrou-se a participação decisiva, em muitos casos, de outros agentes (coordenadores pedagógicos, diretores e, até mesmo, secretarias de educação) na escolha dos livros didáticos, marginalizando do processo o professor, ou seja, aquele que irá de fato utilizar o material com os alunos. Ressaltam que o Guia do Livro Didático tem um papel nulo, na maioria das vezes, no processo de escolha. Tal 


\section{4}

situação é motivada por inúmeros fatores, tais como o desconhecimento dos docentes sobre o processo da avaliação nacional dos livros didáticos e a pouca confiança depositada nessa avaliação. A análise dos dados permitiu às autoras registrar também que os problemas no plano da distribuição ainda são graves. Fatores como estes levam muitos professores a não receberem os livros escolhidos, ampliando a descrença na eficiência do programa. Apontam também as necessidades de mais diálogo entre os que avaliam e os que utilizam o material, para minorar a distância entre o professor e o Guia. Acrescentam a isso a necessidade de investimento na capacitação dos professores, na melhoria das condições de trabalho e no salário como meios de ampliar a autonomia profissional, que redundará, inclusive, num processo mais qualificado de escolha do livro didático.

O trabalho produzido por autores envolvidos diretamente na avaliação oficial dos livros didáticos apresenta uma visão bastante positiva do processo, que é desenvolvido para garantir a qualidade do produto adquirido para a escola pública. Tecendo apenas críticas pontuais ao PNLD, tais como as dificuldades de se encontrar critérios de avaliação em um país de dimensões continentais, o pouco significado que o Guia do Livro Didático possui para os professores de Ensino Fundamental, a ineficiência do processo de distribuição que impede professores de receberem os livros escolhidos, a obra referenda o processo desencadeado pelo MEC para avaliação nacional da produção didática. Entretanto, a seriedade do processo construído ao longo dos dez anos de avaliação promovida pelo MEC, por meio do PNLD, intercalado com momentos de diálogo, menos ou mais conflituoso, com agentes envolvidos na produção e no uso dos livros, é descrita com o distanciamento necessário.

A obra é leitura importante para aqueles que pretendem conhecer melhor o processo de aquisição de livros didáticos para escolas públicas no Brasil, sejam defensores ou críticos deste tipo de política 
governamental. Além de oferecer subsídios para os avanços da pesquisa nesta temática fundamental para a Educação Básica, os autores sugerem questões que precisam ser melhor compreendidas. Entre elas estão as formas de uso e os critérios de escolha adotados pelos professores do Ensino Fundamental que, ao serem pesquisadas, poderão contribuir para o aperfeiçoamento do processo de avaliação das obras didáticas, trazendo à tona as dinâmicas criadas por professores na interação com os livros, na realidade cotidiana das escolas.

Recebimento: 25/09/2007

Aprovação: 25/10/2007

\section{Contato:}

Rua Alair Marques Rodrigues, 812 - Apto202.

Bairro Santa Amélia

Belo Horizonte - MG

CEP: $31560-220$

E-mail: promarco@terra.com.br 